\title{
Исследование взаимосвязи механических напряжений, оптической неоднородности и концентрации кислорода в кристаллах германия
}

\author{
(С) А.Ф. Шиманский ${ }^{1}$, Е.Д. Кравцова ${ }^{1}$, Т.В. Кулаковская ${ }^{2}$, А.П. Григорович ${ }^{2}$, С.А. Копыткова ${ }^{2}$, А.Д. Смирнов $^{3}$ \\ ${ }^{1}$ ФГАОУ ВО „Сибирский фредеральный университет“, \\ 660041 Красноярск, Россия \\ ${ }^{2} \mathrm{AO}$ „Германий“, \\ 660027 Красноярск, Россия \\ ${ }^{3}$ ЗАО „Группа СТP“, \\ 194156 Санкт-Петербург, Россия \\ E-mail: shimanaf@mail.ru
}

Поступила в Редакцию 8 ноября 2021 г.

В окончательной редакции 15 ноября 2021 r.

Принята к публикации 15 ноября 2021 г.

Представлены результаты исследования радиального распределения механических напряжений, концентрации кислорода и оптической неоднородности в кристаллах германия диаметром 200 мм, легированных сурьмой, с удельным электрическим сопротивлением от 10.5 до 18.5 Ом·см, выращенных по методу Чохральского. Установлено, что остаточные напряжения, рассчитанные по данным рентгеноструктурного анализа, коррелируют с результатами численного моделирования термоупругих напряжений и взаимосвязаны со значениями оптической неоднородности и концентрации растворенного кислорода, присутствующего в германии в атомарно-диспергированном состоянии.

Ключевые слова: германий, монокристаллы, механические напряжения, оптическая неоднородность, примесь кислорода.

DOI: $10.21883 /$ FTP.2022.03.52112.9765

\section{1. Введение}

Развитие технологий получения полупроводникового германия направлено на выращивание крупногабаритных монокристаллов с одновременным повышением требований к их структурному совершенству. К наиболее наукоемким и высокотехнологичным отраслям, потребляющим монокристаллический германий высокого качества, обязательным требованием к которому является низкое содержание дефектов, относятся производства инфракрасной оптики, электронных приборов и солнечных батарей [1-4]. Основным типом ростовых дефектов, оказывающих значительное влияние на свойства кристаллов, являются дислокации $[3,4]$. Дислокации нарушают их оптическую однородность и могут приводить к существенному ослаблению светового потока $[5,6]$. Исходя из этого, высокая плотность дислокаций затрудняет применение кристаллов германия в оптике, вместе с тем полностью исключает возможность его использования в фотовольтаике, где Ge используется в качестве подложек для эпитаксиальных структур типа $\mathrm{GaInP} / \mathrm{GaInAs} / \mathrm{Ge}$, являющихся основой фотопреобразователей. Наличие дислокаций приводит к несоответствию параметров кристаллических решеток $\mathrm{Ge}$ и соединений $\mathrm{A}^{\mathrm{III}} \mathrm{B}^{\mathrm{V}}$, препятствуя росту высококачественных эпитаксиальных слоев на германиевой подложке [1-3]. Наряду с этим бездислокационный германий обеспечивает преимущества в быстродействии по сравнению с кремнием при создании радиационно стойких силовых MOSFET-транзисторов [7].
Известно, что формирование дислокационной структуры происходит в ходе выращивания кристаллов под действием внутренних макронапряжений. Наибольший вклад в возникновение напряжений в растущем кристалле вносят неоднородное температурное поле, вызывающее появление термоупругих напряжений, а также гетерогенные и гомогенные примесные неоднородности, определяющие остаточные напряжения [3-5,7-12].

В работах $[8,9]$ показано, что одной из основных примесей, от которых зависит образование дефектов в германии, является кислород. Вблизи фронта кристаллизации в результате взаимодействия германия с остаточным кислородом в среде выращивания могут образовываться высокодисперсные частицы $\mathrm{GeO}_{2}$, которые захватываются в объем кристалла, создавая гетерогенные включения, являющиеся центрами образования дислокаций. С целью удаления частиц оксида германия в расплаве авторы работ $[8,9]$ предлагают выращивать кристаллы Ge из-под слоя флюса $\mathrm{B}_{2} \mathrm{O}_{3}$. Установлено, что в монокристалле, выращенном без участия $\mathrm{B}_{2} \mathrm{O}_{3}$, плотность дислокаций составляла $4 \cdot 10^{3} \mathrm{~cm}^{-2}$, и, напротив, в кристалле, полученном в идентичных условиях, но с добавлением $\mathrm{B}_{2} \mathrm{O}_{3}$, дислокации не были обнаружены. Концентрация кислорода в исследуемых кристаллах составляла $2.3 \cdot 10^{16}$ и $8.5 \cdot 10^{15} \mathrm{~cm}^{-3}$ соответственно $[8,9]$.

Из работ [7,10-12] известно, что растворенный атомарный кислород также оказывает влияние на структурное совершенство кристаллов. В работе [10] обсуждается диффузионная модель дефектообразования, которая исходит из приоритета следующих точечных 


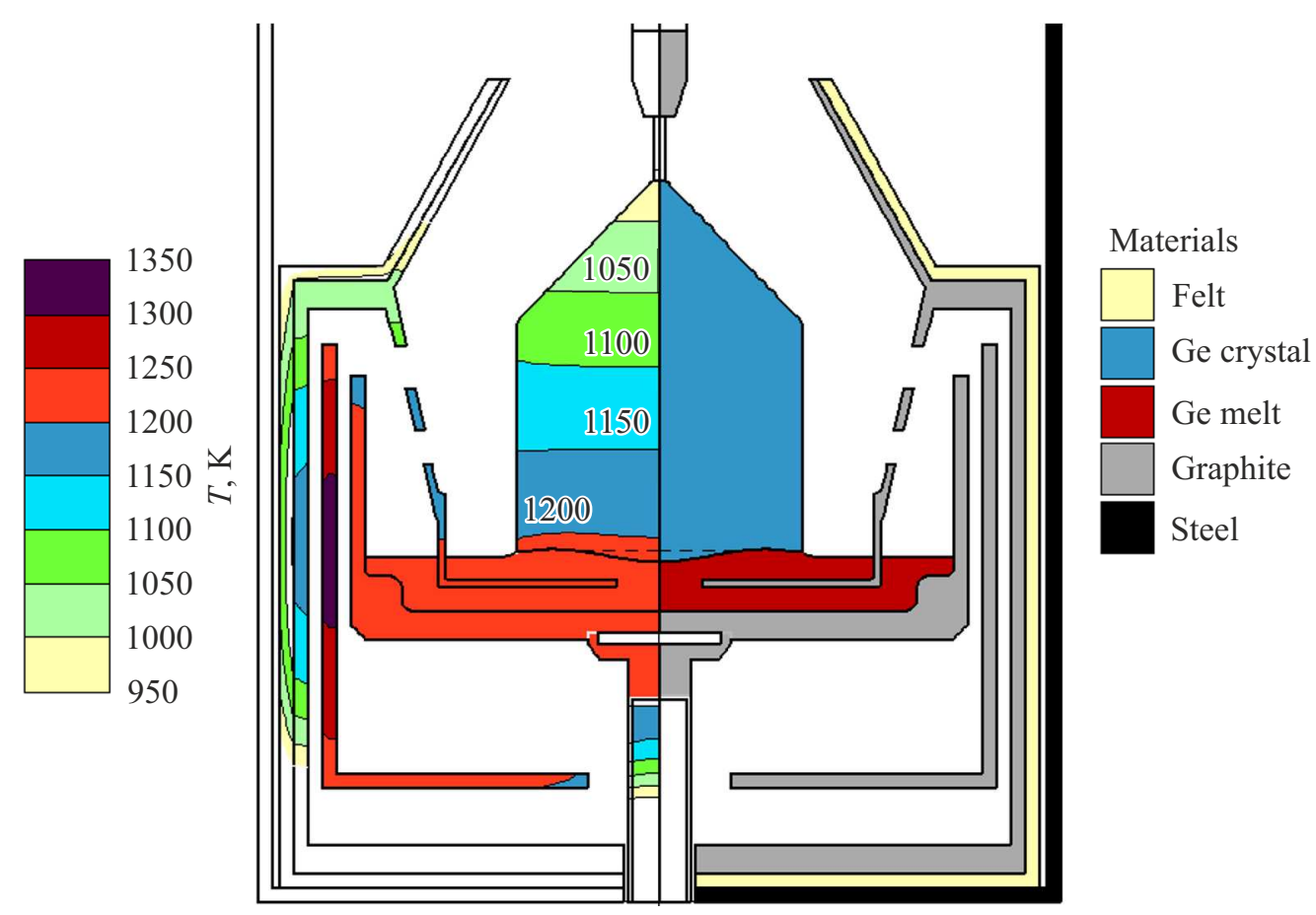

Рис. 1. Схема теплового узла с внутренним тиглем.

дефектов в формировании нарушений кристаллической структуры: собственных - вакансий и межузельных атомов, примесных - атомов в узлах решетки или междоузлиях, а также их ассоциатов с собственными дефектами [7,11]. Развиваемые авторами работы [10] представления базируются на процессе высокотемпературной преципитации атомарного кислорода с собственными дефектами, приводящей к образованию комплексов „кислород-германий“. Отмечается, что во время охлаждения кристалла могут происходить рост и коалесценция преципитатов с образованием дислокаций. С другой стороны, в работе [12] констатируется, что влияние ассоциатов, образующихся в результате взаимодействия и сегрегации точечных дефектов с участием кислорода, может приводить к торможению процесса зарождения дислокаций, что открывает, по мнению авторов данной работы, возможность снижения дефектности кристаллов путем их легирования кислородом. Таким образом, данные по влиянию растворенного в германии кислорода на дефектную структуру кристаллов имеют противоречивый характер, закономерности влияния распределения примеси кислорода в объеме кристаллов германия на формирование в них напряжений и неоднородности свойств, а также образование дислокаций, в литературе не найдены.

Цель данной работы - исследование радиального распределения примеси кислорода, присутствующего в германии в атомарно-диспергированном состоянии в количестве, не превышающем предел растворимости, анализ взаимосвязи концентрации растворенного кислорода, механических напряжений и неоднородности показателя преломления в кристаллах, выращенных по методу Чохральского.

\section{2. Экспериментальная часть}

Монокристаллы германия диаметром 200 мм выращивали методом Чохральского на установке типа „Редмет“ в вакууме при остаточном давлении $1.5 \cdot 10^{-2}$ Па, со скоростью $0.2 \mathrm{Mм} / \mathrm{Mин,} \mathrm{скорость} \mathrm{вращения} \mathrm{затравки} \mathrm{была}$ 12 об/мин, тигля - 6 об/мин. Средняя плотность дислокаций в кристаллах составляла $10^{4} \mathrm{~cm}^{-2}$. Для исключения влияния образующихся в расплаве частиц оксида германия на рост кристалла использовали конструкцию теплового узла с внутренним тиглем, схема которого представлена на рис. 1.

Тепловой узел включает изготовленные из графита основной тигель диаметром 430 мм, графитовый нагреватель и тепловые экраны, на внешней поверхности которых размещается слой теплоизоляции из графитового термовойлока толщиной 10 мм. Выращивание кристаллов производилось из стационарно закрепленного внутреннего тигля диаметром 300 мм, который предотвращает доступ взвешенных в расплаве оксидных частиц из основной массы расплава к фронту кристаллизации.

В качестве загрузки использовали германий, поликристаллический зонноочищенный (ГПЗ) марки 6N. Выращивали монокристаллы $n$-типа проводимости, легированные сурьмой. Легирующую примесь $\mathrm{Sb}$ (марки $6 N$ ) вводили в чистом виде в исходную загрузку для получения монокристаллов с УЭС от 10.5 до 18.5 Ом · см. Направление роста кристаллов - [111]. 
Для моделирования процесса выращивания применяли мультифизический пакет CGSim [13], который позволяет на основе решения совмещенной задачи тепломассопереноса с учетом гидродинамики расплава определить форму фронта кристаллизации и распределение тепловых потоков в ростовой системе, а также рассчитать температурные поля и соответствующие термоупругие напряжения в растущем кристалле.

Для экспериментального определения содержания кислорода $\left[\mathrm{O}_{i}\right]$ в кристаллах $\mathrm{Ge}$ применяли метод ИК фурье-спектрометрии. Образцы для оптических исследований имели форму плоскопараллельных пластин диаметром 20 мм и толщиной 10 мм, вырезанных из кристалла в направлении [111]. Рабочие поверхности пластин были подготовлены по технологии химико-механической оптической обработки до VI класса (ГОСТ 11141-84), шероховатость полированных поверхностей соответствовала $R z \leq 0.05$ мкм (на базовой длине 0.08 мм по ГОСТ 2789-73).

Регистрацию ИК-спектров поглощения производили с использованием ИК фурье-спектрометра SPECTRUM BXII. Погрешность измерений оптической плотности не превышала \pm 0.001 . Концентрацию кислорода в образце определяли так же, как в работах $[14,15]$, по величине оптической плотности $D$ на волновом числе $841 \pm 2 \mathrm{~cm}^{-1}$ по формуле

$$
\left[\mathrm{O}_{i}\right]=1.05 \cdot 10^{17}\left(\frac{2.3 D}{d}\right)
$$

где $D-$ оптическая плотность относительно базовой линии, соответствующая „кислородному пику; $d-$ толщина образца; $1.05 \cdot 10^{17}-$ градуировочный коэффициент, $\mathrm{cm}^{-2}[3]$.

Съемку рентгенограмм проводили на дифрактометре X'Pert PRO (PANalytical) с вертикальным гониометром и полупроводниковым однокоординатным детектором PIXcel, снабженным графитовым монохроматором. Дифракционные измерения проводились в угловом интервале $2 \theta$ от 20 до $144^{\circ}$, по участкам, содержащим линии $(h k l)$, с шагом $0.013^{\circ}$ и временем накопления 50 с в каждой точке. Съемка проводилась при вращении образца со скоростью 1 об/с. Угловое положение рефлекса определялось с помощью стандартного программного обеспечения X'Pert PRO с использованием $\mathrm{Cu} K_{\alpha 1}$ составляющей. Съемки проводились в закрытой защитной кабине дифрактометра при стабилизированной температуре $24^{\circ} \mathrm{C}$. Расчеты параметра решетки были выполнены по методу Нельсона-Райли с использованием экстраполяционной функции

$$
f(\theta)=\frac{1}{2}\left(\frac{\cos ^{2} \theta}{\sin \theta}+\frac{\cos ^{2} \theta}{\theta}\right)
$$

где $\theta-$ угол дифракции. Построения выполнены для рефлексов [111], [222], [333], [444]. Точность расчета параметра решетки составляет $\pm 0.0001 \AA$.
Исследование оптической однородности проведено в $\mathrm{AO}$ „Государственный оптический институт им. С.И. Вавилова“. Интерферометрический контроль образца на просвет производился на ИК-интерферометре ИКИ-10 на длине волны 10.6 мкм, контроль формы поверхностей пластины - на интерферометре ИКД 110 с длиной волны источника излучения 0.6328 мкм. Оптическая однородность определена для 5 областей диаметром 50 мм. Расположение исследуемых образцов в кристалле и вид интерферограммы поверхности представлены на рис. 2.

\section{3. Результаты и обсуждение}

Эффекты неоднородного распределения примесей и структурно чувствительных свойств наиболее ярко могут быть выражены в кристаллах большого объема, поэтому исследования были проведены на монокристаллах диаметром 200 мм. На рис. 2 представлена фотография монокристалла и показаны места отбора образцов.

В программном пакете CGSim моделировались форма фронта кристаллизации и термоупругие напряжения, возникающие как следствие неоднородности температурного поля в кристалле. На рис. 3 представлены результаты численного моделирования формы фронта кристаллизации растущего слитка на разной высоте $(h)$.

Из рис. 3 следует, что вблизи оси роста фронт кристаллизации - выпуклый. Отклонение от плоскости $\Delta h$ составляет 10 мм. Вблизи поверхности слитка наблю-

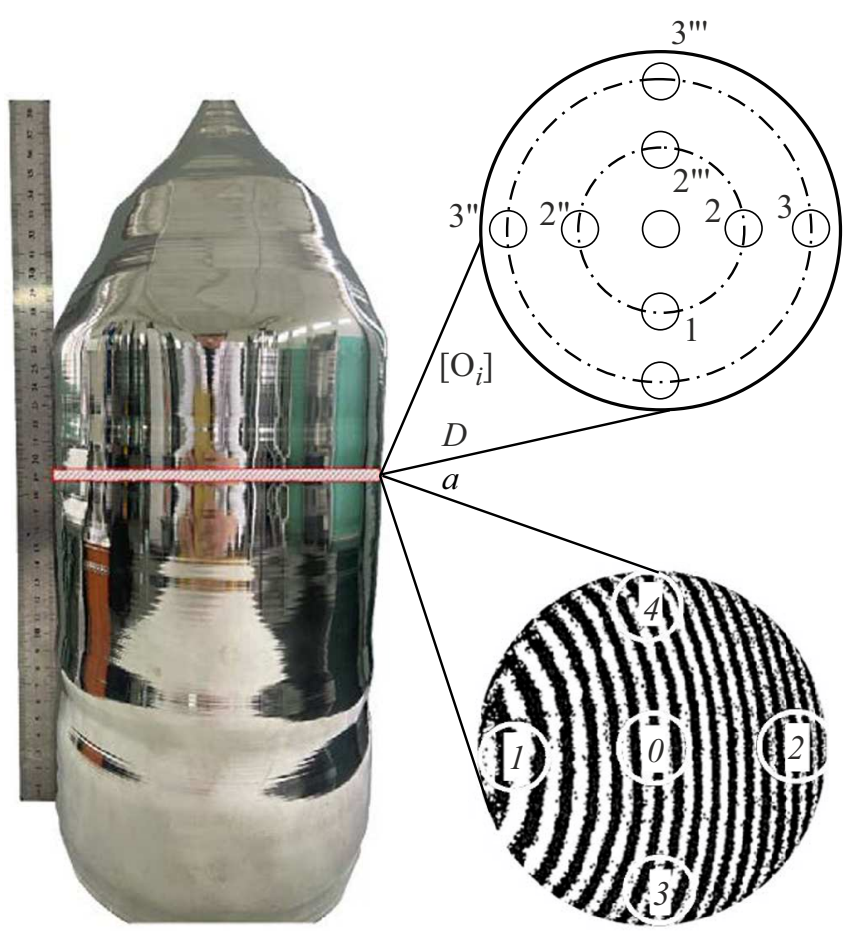

Рис. 2. Фотография кристалла диаметром 200 мм и места отбора образцов для определения оптической плотности $D$, концентрации растворенного кислорода $\left[\mathrm{O}_{i}\right]$, параметра кристаллической решетки $a$ и оптической неоднородности $\Delta n$. 
Рентгеновские данные, значения $\Delta a / a$ и остаточные напряжения, рассчитанные на их основе

\begin{tabular}{|c|c|c|c|c|c|c|c|c|}
\hline $\begin{array}{l}\text { Номер } \\
\text { образца }\end{array}$ & $2 \theta,\left({ }^{\circ}\right)$ & $h k l$ & $d$ & $a_{h k l}$ & $f(\theta)$ & $\begin{array}{c}\text { Параметр решетки, } a \\
\pm 1 \cdot 10^{-4}, \AA\end{array}$ & $\Delta a / a, 10^{-5}$ & $\begin{array}{c}\text { Остаточные } \\
\text { напряжения, } \sigma, \text { МПа }\end{array}$ \\
\hline 1 (центр) & $\begin{array}{r}27.322 \\
56.313 \\
90.085 \\
141.232\end{array}$ & $\begin{array}{l}111 \\
222 \\
333 \\
444\end{array}$ & $\begin{array}{l}3.26146 \\
1.63236 \\
1.08853 \\
0.81657\end{array}$ & $\begin{array}{l}5.64900 \\
5.65466 \\
5.65619 \\
5.65734\end{array}$ & $\begin{array}{l}3.979055 \\
1.614542 \\
0.670305 \\
0.103077\end{array}$ & 5.6577 & 3.0 & 3.1 \\
\hline $\begin{array}{l}2 \text { (средина } \\
\text { радиуса) }\end{array}$ & $\begin{array}{r}27.356 \\
56.345 \\
90.111 \\
141.244\end{array}$ & $\begin{array}{l}111 \\
222 \\
333 \\
444\end{array}$ & $\begin{array}{l}3.25748 \\
1.63151 \\
1.08829 \\
0.81654\end{array}$ & $\begin{array}{l}5.64212 \\
5.65171 \\
5.65491 \\
5.65713\end{array}$ & $\begin{array}{l}3.973583 \\
1.613180 \\
0.669829 \\
0.103009\end{array}$ & 5.6576 & 2.0 & 2.1 \\
\hline 3 (край) & $\begin{array}{r}27.399 \\
56.381 \\
90.133 \\
141.265\end{array}$ & $\begin{array}{l}111 \\
222 \\
333 \\
444\end{array}$ & $\begin{array}{l}3.25246 \\
1.63055 \\
1.08808 \\
0.81648\end{array}$ & $\begin{array}{l}5.63343 \\
5.64840 \\
5.65382 \\
5.65677\end{array}$ & $\begin{array}{l}3.966681 \\
1.611651 \\
0.669427 \\
0.102892\end{array}$ & 5.6578 & 5.0 & 5.2 \\
\hline
\end{tabular}

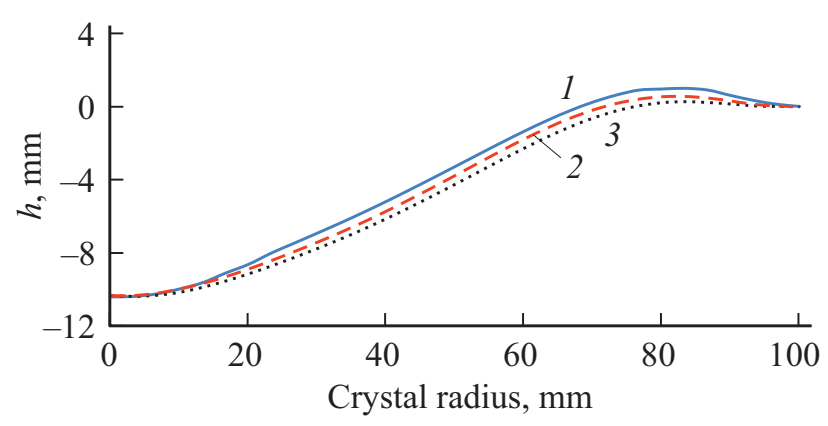

Рис. 3. Форма фронта кристаллизации на высоте слитка, мм: $1-110,2-180,3-250$.

дается изменение кривизны фронта кристаллизации, свидетельствующее о нарушении однородности температурного поля и, соответственно, о возможности возникновения повышенных напряжений [1]. Полученные расчетные данные соответствуют экспериментальным данным работы [16], авторы которой также наблюдали в верхней половине кристаллов диметром 160 мм выпуклый фронт кристаллизации с искривлением на краю слитка.

На рис. 4 представлено распределение модуля радиального градиента температуры и термоупругих напряжений в кристаллах в моделируемых условиях. Из расчетных данных (см. рис. 4) следует, что максимальный по абсолютной величине радиальный градиент температуры наблюдается у края слитка и достигает $150 \mathrm{~K} / \mathrm{M}$. Повышенные напряжения ( $2.0 \mathrm{MПа})$ прослеживаются в центре кристалла, а максимальные $(\sim 2.5 \mathrm{MПа})$ наблюдаются вблизи боковой поверхности.

Концентрация напряжений в центре и на периферии кристалла является характерной для слитков, выращиваемых на установках типа „Редмет“ с применяемой модификацией теплового узла [17].

Радиальное распределение напряжений определено также экспериментально с использованием данных рентгеновского структурного анализа по величине относи- тельного отклонения параметра решетки $\Delta a / a$ исследуемых образцов. На основании результатов работы [18] в качестве эталонного значения $a$ принято $5.6575 \AA$. Усредненные результаты расчета параметра решетки $a$ для исследуемых образцов приведены в таблице.

Значения $\Delta a / a$ в центре кристалла $\left(3.0 \cdot 10^{-5}\right)$ и вблизи поверхности $\left(5.0 \cdot 10^{-5}\right.$ превышают $\Delta a / a$ посредине радиуса кристалла $\left(2.0 \cdot 10^{-5}\right)$. Так как значения $\Delta a / a$ отвечают деформации кристалла $(\varepsilon)$, по полученным данным с учетом модуля упругости $(E)$, равного $10^{3}$ ГПа, можно оценить остаточные напряжения в исследуемых образцах $(\sigma)$ [3,5]. Рассчитанные по величине $\Delta a / a$ остаточные напряжения $(\sigma=\varepsilon \cdot E)$ изменяются от 2.1 до 5.2 МПа с максимумами в центре и на периферии кристалла.

Механические напряжения и, соответственно, дислокационные дефекты являются источниками аномалий оптических свойств и снижают оптическую однородность

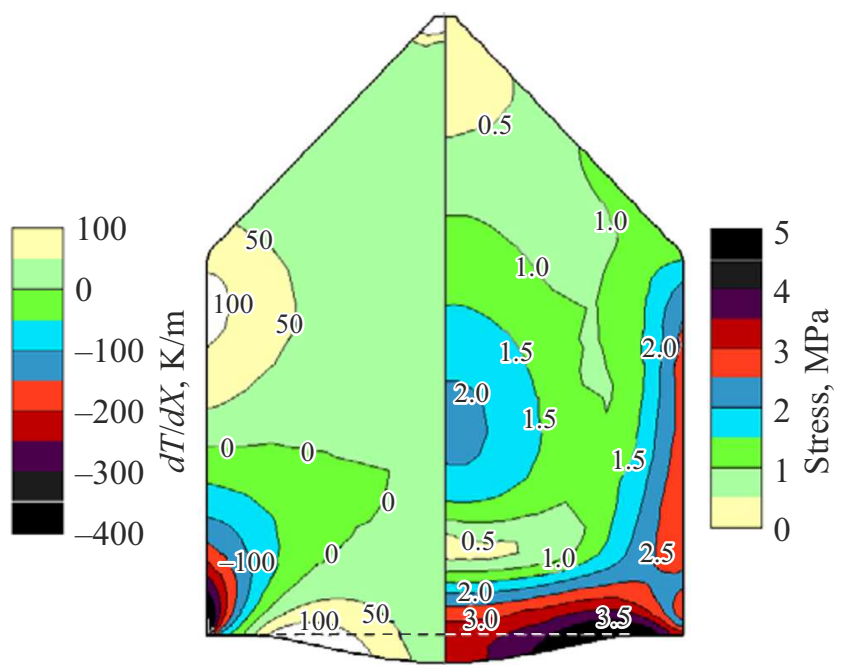

Рис. 4. Радиальное распределение градиента температуры и термоупругих напряжений. 


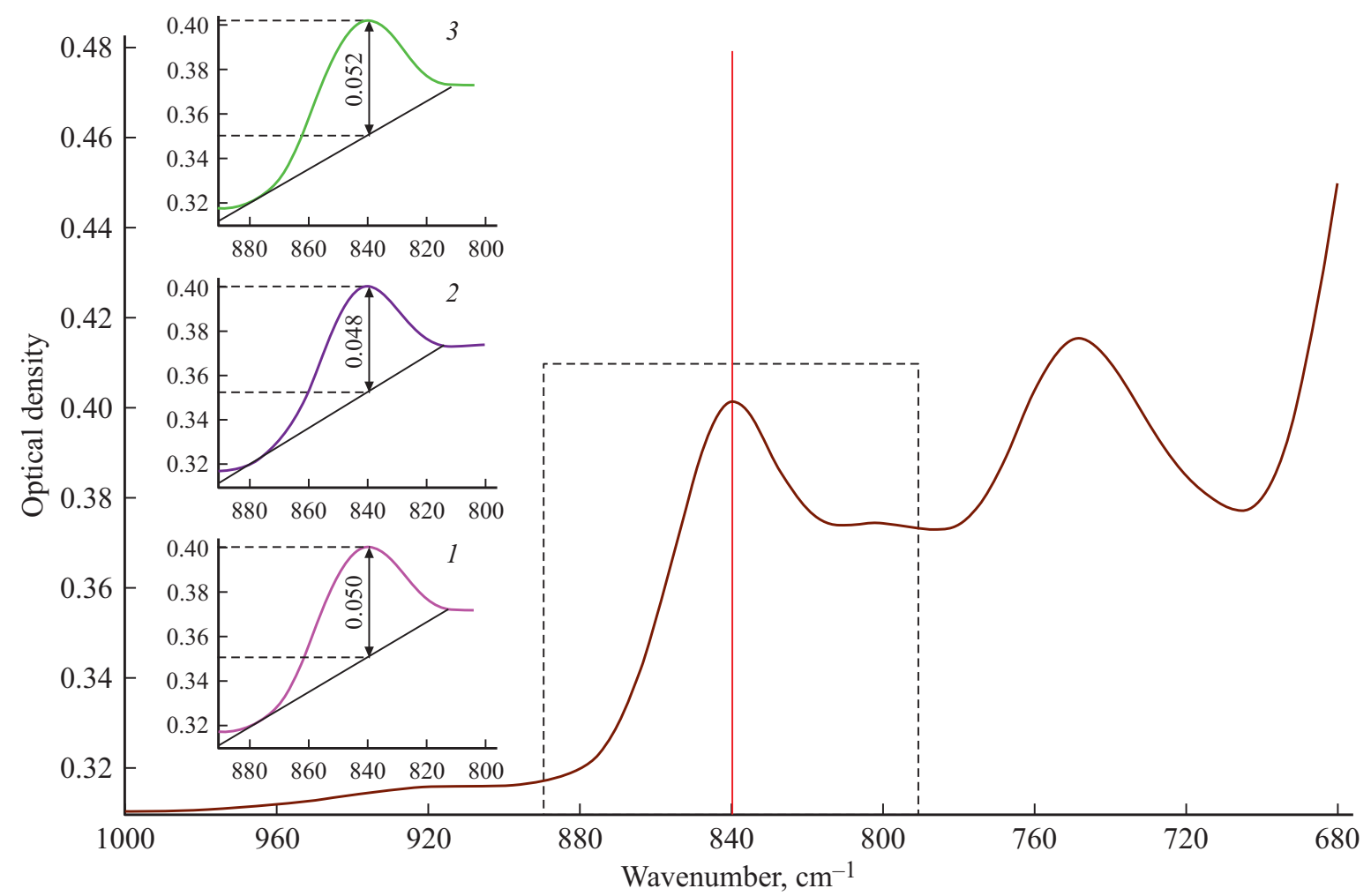

Рис. 5. Общий вид ИК-спектра поглощения кристалла германия, легированного сурьмой, и кислородная полоса для трех исследуемых образцов: 1 - центр кристалла, 2 - середина радиуса, 3 - край.

кристаллов. Были проведены интерферометрические исследования оптической однородности образцов по измеренной топографии деформаций волнового фронта, прошедшего через контролируемый образец.

По результатам измерений установлено, что оптическая неоднородность $\Delta n$ в центре кристалла составляет $0.9 \cdot 10^{-5}$, среднее значение $\Delta n$ на периферии кристалла $-\sim 4.5 \cdot 10^{-5}$.

В исследуемых образцах определено содержание кислорода. В монокристаллическом германии оптически активный кислород занимает межузельные позиции $\mathrm{O}_{i}$, образуя квазимолекулу $\mathrm{Ge}-\mathrm{O}-\mathrm{Ge}$, которая электрически не заряжена и имеет ряд собственных частот колебаний. На рис. 5 приведен общий вид ИК-спектра поглощения монокристаллического германия, легированного сурьмой, в интервале волновых чисел $680-1000 \mathrm{~cm}^{-1}$ и кислородная полоса на волновом числе $841 \pm 2 \mathrm{~cm}^{-1}$ для экспериментальных образцов, вырезанных последовательно по радиусу кристалла - в центре, посредине и на краю сечения на высоте 200 мм.

По величине оптической плотности в максимуме полосы относительно базовой линии была определена концентрация атомарного кислорода в исследуемых кристаллах германия. Установлено, что усредненная концентрация кислорода в исследуемом кристалле германия в направлении от центра к краю изменяется в следующем порядке $\left(10^{16} \mathrm{~cm}^{-3}\right): 1.20$ (в центре кристалла), 1.10 и 1.30 - на краю, как показано на рис. 6.
Таким образом, наблюдается корреляция между радиальным распределением остаточных напряжений и концентрации кислорода, коэффициент корреляции составляет 0.97, областям кристалла в центре и на периферии соответствуют как повышенные остаточные напряжения, так и содержание кислорода.

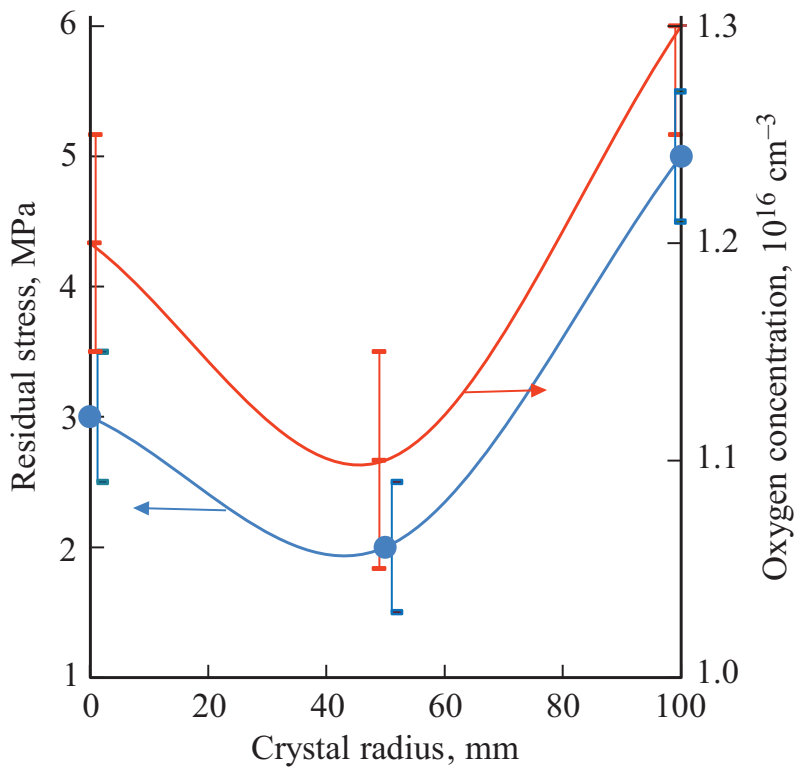

Рис. 6. Взаимосвязь концентрации кислорода и остаточных напряжений. 


\section{4. Заключение}

Остаточные напряжения, определенные по данным рентгеноструктурного анализа, коррелируют с прогнозируемыми на основе численного моделирования в программе CGSim термоупругими напряжениями и взаимосвязаны со значениями концентрации растворенного в германии кислорода и оптической неоднородности, что может служить подтверждением гипотезы о влиянии растворенного кислорода на формирование структуры и свойств кристаллов германия.

\section{Благодарности}

Работа выполнена с использованием оборудования Красноярского регионального центра коллективного пользования ФИЦ КНЦ СО РАН.

\section{Финансирование работы}

Работа выполнена при финансовой поддержке Министерства науки и высшего образования Российскои. Федерации, программа Научно-технологическое развитие РФ, проект FSRZ-2020-0013.

\section{Конфликт интересов}

Авторы заявляют, что у них нет конфликта интересов.

\section{Список литературы}

[1] F. Dimroth, S. Kurtz. MRS Bull., 32(3), 230 (2007). DOI: $10.1557 / \mathrm{mrs} 2007.27$

[2] A. Luque, S. Hegedus. Handbook Photovoltaic Science and Engineering (John Wiley \& Sons Ltd., Chichester, 2003).

[3] C.L. Claeys, E. Simoen. Germanium-Based Technologies: from Materials to Devices (Elsevier B.V, Amsterdam, 2007).

[4] C.L. Claeys, E. Simoen.Extended Defects in Germanium: Fundamental and Technological Aspects (Springer, Berlin [etc.], 2009).

[5] B. Depuydt, A. Theuwis, I. Romandic. Mater. Sci. Semicond. Process., 9(4-5), 437 (2006). DOI: $10.1016 /$ j.mssp.2006.08.002

[6] K. Seref, I. Romandic, A. Theuwis. Mater. Sci. Semicond. Process., 9(4-5), 753 (2006). DOI: $10.1016 /$ j.mssp.2006.08.035

[7] A. Chroneos, R.V. Vovk. J. Mater. Sci. Mater. Electron., 26 (10), 7378 (2015). DOI: 10.1007/s10854-015-3367-7

[8] T. Taishi, Y. Ohno, I. Yonenaga. J. Cryst. Growth, 311 (22), 4615 (2009). DOI: 10.1016/j.jcrysgro.2009.09.001

[9] T. Taishi, H. Ise, Y. Murao, T. Osawa, M. Suezawa, Y. Tokumoto, Y. Ohno, K. Hoshikawa, I. Yonenaga. J. Cryst. Growth, 312 (19), 2783 (2010). DOI: $10.1016 /$ j.jcrysgro.2010.05.045

[10] V.I. Talanin, I.E. Talanin. J. Cryst. Growth, 552125928 (2020). DOI: 0.1016/j.jcrysgro.2020.125928

[11] K. Sueoka, J. Vanhellemont. Mater. Sci. Semicond. Process., 9 (4-5), 494 (2006). DOI: 10.1016/j.mssp.2006.08.004
[12] Y. Murao, T. Taishi, Y. Tokumoto, Y. Ohno, I. Yonenaga. J. Appl. Phys., 109 (11), 113502 (2011). DOI: $10.1063 / 1.3592226$

[13] CGSim package for analysis and optimization of $C z$, $L E C, V C z$, and Bridgman growth of semiconductor and semitransparent crystals // STR [site]. URL: http://www.str-soft.com/products/CGSim/

[14] A.F. Shimanskii, O.I. Podkopaev, V.N. Baranov. Adv. Mater. Res., 1101, 115 (2015).

DOI: 10.4028/www.scientific.net/AMR.1101.115

[15] И.А. Каплунов, В.Е. Рогалин, М.Ю. Гавалян. Опт. и спектр., 118 (2), 254 (2015).

DOI: $10.7868 / \mathrm{S} 0030403415020087$ [I.A. Kaplunov, V.E. Rogalin, M.Y. Gavalyan. Opt. Spectrosc., $118(2), 240$ (2015). DOI: $10.1134 / \mathrm{S} 0030400 X 15020083$

[16] M. Roth, M. Azoulay, G. Gafni, M. Mizrachi. J. Cryst. Growth, $99(1-4), 670$ (1990)

[17] V.V. Artemyev, A.D. Smirnov, V.V. Kalaev, V.M. Mamedov, A.P. Sidko, O.I. Podkopaev, E.D. Kravtsova, A.F. Shimansky. J. Cryst. Growth, 468, 443 (2017). DOI: $10.1016 /$ j.jcrysgro.2017.01.032

[18] A.S. Cooper. Acta Cryst., 15, 578 (1962). DOI: $10.1107 / \mathrm{S} 0365110 \times 62001474$

Редактор А.Н. Смирнов

\section{Study of relation between mechanical stress, optical inhomogeneity and oxygen concentration in germanium crystals}

A.F. Shimanskii ${ }^{1}$, E.D. Kravtsova ${ }^{1}$, T.V. Kulakovskaya ${ }^{2}$, A.P. Grigorovich ${ }^{2}$, S.A. Kopytkova ${ }^{2}$, A.D. Smirnov ${ }^{3}$

${ }^{1}$ Siberian Federal University, 660041 Krasnoyarsk, Russia

2 JSC Germanium, 660027 Krasnoyarsk, Russia

${ }^{3}$ STR Group, Inc., 194156 St. Petersburg, Russia

Abstract The radial distribution of mechanical stress, optical inhomogeneity and oxygen concentration in Sb-doped germanium crystals grown by the Czochralski method with diameter of $200 \mathrm{~mm}$ and resistivity from 10.5 to $18.5 \Omega \cdot \mathrm{cm}$ were studied. It was found that residual stress calculated from the data of $X$-ray structural analysis correlates with results of numerical simulation of thermoelastic stress and interrelates with optical inhomogeneity and concentration of oxygen presented in the atomically dispersed state in germanium. 